\title{
The significance of phosphorus 'hot spots' and micron-sized grains in Quaternary forest soils
}

\author{
GBOTEMI A. ADEDIRAN ${ }^{1}$, MELANIE KIELMAN- \\ SCHMITT $^{2}$, ELLEN KOOIJMAN ${ }^{2}$ AND JON PETTER \\ GUSTAFSSON $^{1}$
}

${ }^{1}$ Swedish University of Agricultural Sciences

${ }^{2}$ Swedish Museum of Natural History

Presenting Author: GboAde@ceh.ac.uk

Recent advances in soil phosphorus (P) studies have revealed unique $\mathrm{P}$ 'hot spots' and discrete micron-sized grains at soil microsites[1, 2], but the significance of these so-called 'hot spots' and grains in P cycling and long-term supply is yet to be determined.

We revealed soil architecture at a micro-scale in two postglacial forest soils in Sweden by micro-focused synchrotron X-ray fluorescence microscopy and laser ablation (LA)-ICPMS imaging. This allowed us to quantitatively establish both axial and lateral abundance, distribution, and co-localization of $\mathrm{P}$ with elements known to influence its speciation (e.g., Si, Al, Mn, Ca, and $\mathrm{Fe}$ ).

The results show topsoil $\mathrm{P}$ to be co-localized predominantly with $\mathrm{Si}, \mathrm{Al}$ and $\mathrm{Fe}$. However, in the subsoils, $\mathrm{P}$ was co-localized mainly with $\mathrm{Ca}$ in hot spots within $\mathrm{Si}$ and Al-bearing minerals and in micron-sized grains. $\mathrm{P}$ concentrations in these hot spots and grains were from 7 to 600 times greater than the average soil $\mathrm{P}$ concentrations, with the highest values $(2,542-8,716 \mathrm{mmol} \mathrm{P}$ $\mathrm{kg}^{-1}$ ) occurring at the $90-100 \mathrm{~cm}$ depths in the two soils.

When combined with previous results of $\mathrm{P}$ speciation analysis by synchrotron $\mathrm{P} K$-edge XANES in the same soils[1], our work firmly establishes geogenic apatite to have been dissolved in the top-soil and its $\mathrm{P}$ transformed to $\mathrm{P}$ adsorbed by allophane and ferrihydrite, and as organic P. Most importantly, our work shows sub-soil hot spots of apatite inclusions and micron-sized grains to be a long-term source of $\mathrm{P}$ that trees could potentially utilize.

1. Adediran, G. A.; Tuyishime, J. M.; Vantelon, D.; Klysubun, W.; Gustafsson, J. P., Geoderma 2020, 376, 114550

2. Vogel, C.; Helfenstein, J.; Massey, M. S.; Sekine, R.; Kretzschmar, R.; Beiping, L.; Peter, T.; Chadwick, O. A.; Tamburini, F.; Rivard, C., Geoderma 2021, 381, 114681 